\title{
Effect of MWNTs and SiC-Coated MWNTs on Properties of PEEK/LCP Blend
}

\author{
Ganesh Chandra Nayak, R. Rajasekar, Saswata Bose, and Chapal Kumar Das
}

Materials Science Center, Indian Institute of Technology, Kharagpur 721302, India

Correspondence should be addressed to Ganesh Chandra Nayak, gcnayak_bls@yahoo.co.in

Received 18 May 2009; Accepted 2 September 2009

Recommended by Charles M. Lukehart

\begin{abstract}
Multiwall carbon nanotubes (MWNTs) were modified with polycarbosilane-derived silicon carbide (SiC) to improve its dispersion in the polymer matrix. PEEK/LCP/MWNTs nanocomposites were prepared by melt blending. TEM images show the improved dispersion of SiC-coated MWNTs against agglomerated structure of pure MWNTs in the blend. FESEM images shows better fibrillation of LCP in presence of SiC-coated MWNTs. TGA reveals that nanocomposites with SiC-coated MWNTs shows higher thermal stability than MWNTs filled blend system. Based on enhanced dispersion, storage modulus, tensile modulus and tensile strength were increased drastically with the incorporation of SiC-coated MWNTs. Glass transition temperature of the nanocomposites shows significant improvement with the incorporation of MWNTs.
\end{abstract}

Copyright () 2009 Ganesh Chandra Nayak et al. This is an open access article distributed under the Creative Commons Attribution License, which permits unrestricted use, distribution, and reproduction in any medium, provided the original work is properly cited.

\section{Introduction}

Polymer blends have been developed for improvement of either a specific property or providing materials with a full set of required properties at the low price, improving processability and offering the means for industrial plastic waste recycling [1]. Polymer blends containing thermotropic liquid crystalline polymers (LCPs) considered as one of the most attractive research topic in recent years due to advantages like high processability and less abrasion to the processing machines. Several processing-related studies of this type of blend systems have been published in literature [2-5].

Poly(ether ether ketone) (PEEK) is a semicrystalline, high-performance thermoplastic with excellent mechanical properties such as elastic modulus, strength and toughness, excellent resistance to hydrolysis, and high thermal stability which resulted in its extensive applications in aerospace and marine industries as a load bearing structural material [6]. PEEK has been blended with LCP to improve its processability but the blend shows lower thermal stability than pure PEEK [7]. But the incorporation of carbonnanofibre into the PEEK matrix increases its thermal and mechanical properties significantly $[8,9]$.
Carbon nanotubes (CNTs) have been considered as an ideal reinforcement to fabricate high-performance nanocomposites due to its excellent physical properties, such as high mechanical strength and electrical and thermal conductivity [10]. However the major challenges associated with development of high-performance nanocomposites are uniform dispersion of CNTs in the polymer matrix and developing a strong interfacial interaction which will lead to the effective load transfer from the polymer to the CNTs. In a very recent article [11] MWNTs coated with SiC were used to improve the dispersion of MWNTs in the polymer matrix.

In this study, the overall goal was to develop PEEK/ LCP/MWNTs nanocomposites and determine the effect of MWNTs on thermal and mechanical properties of PEEK/LCP blend system. The effect of SiC-coated MWNTs on the properties of PEEK/LCP blend is also studied with special attention to the dispersion in the blend system.

\section{Experimental Details}

2.1. Materials and Procedure. The PEEK material used here, Victrex 380G, was supplied by ICI. The thermotropic liquid crystalline polymer used was Vectra B 950(LCP), a copolymer based on 6-hydroxy-2-napthoic acid (60\%), 


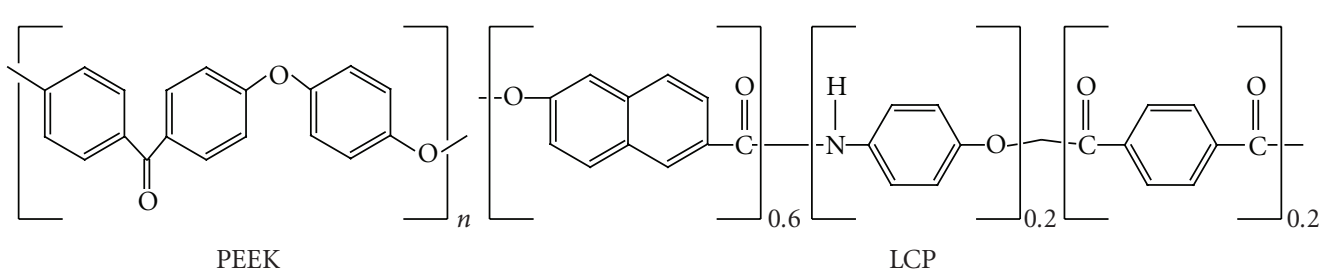

FIgUre 1: Chemical Structure of PEEK and LCP.

terephthalic acid (20\%), and aminophenol (20\%) obtained from Ticona (USA) (the chemical structures were given in Figure 1). The MWNTs (MWNTs-1000) were obtained from IIjini Nanotechnology, South Korea. These MWNTs are having a diameter of $10-20 \mathrm{~nm}$, length $20 \mu \mathrm{m}$, and aspect ratio of $\sim 1000$. The SiC-coated MWNTs were prepared following a method already reported in the literature [11].

2.2. Preparation of Nanocomposites. Prior to mixing, PEEK and LCP were dried under vacuum at $80^{\circ} \mathrm{C}$ and MWNTs (both unmodified and modified) at $300^{\circ} \mathrm{C}$ for 12 hours. A sigma high-temperature internal mixture equipped with two Sigma type counter rotating rotors was used for the preparation of PEEK/LCP/MWNTs composites, at a temperature of $350^{\circ} \mathrm{C}$ with a rotor speed of $100 \mathrm{rpm}$. The formulations of the composites were given in Table 1. The composites were compression molded at $350^{\circ} \mathrm{C}$ and under a constant pressure of $15 \mathrm{MPa}$ for 10 minutes and allowed to cool to room temperature under the same pressure.

\section{Characterization}

3.1. Rheology. Rheology study was carried out in a Capillary Rheometer (Smart RHEO 1000, CEAST) at $360^{\circ} \mathrm{C}$, at different shear rates, to investigate the effect of MWNTs on viscosity of PEEK/LCP blend.

3.2. Fourier Transform Infrared Spectroscopy (FTIR). FTIR of nanocomposites was done using an NEXUS 870 FTIR (Thermo Nicolet) to investigate the possible interaction between PEEK and LCP.

3.3. High Resolution Transmission Electron Microscopy (HRTEM). High-resolution transmission electron microscopy (HR-TEM, JEOL 2100) analysis was performed on MWNTs filled samples, microtomed at room temperature, to investigate the dispersion of MWNTs in the blend system at an accelerating voltage of $120 \mathrm{kV}$.

3.4. Thermogravimetric Analysis (TGA). Thermogravimetric analysis curves were recorded with a Dupont 2100 thermogravimetric analyzer. The TGA measurements were conducted with a heating rate of $10^{\circ} \mathrm{C} / \mathrm{min}$ under an air atmosphere from 50 to $650^{\circ} \mathrm{C}$.

3.5. Dynamic Mechanical Thermal Analysis (DMTA). Dynamic Mechanical analysis was performed on the composite samples using TA Instrument (DMA 2980 model) in single

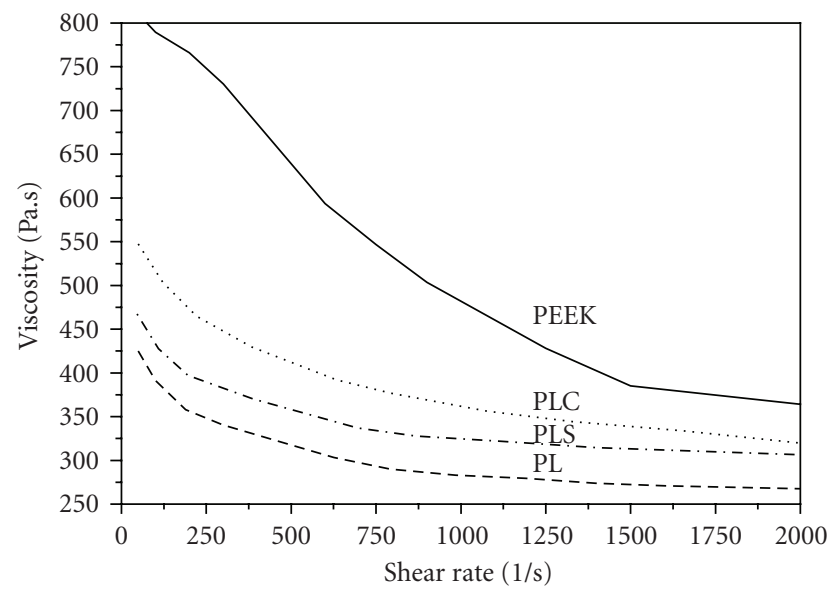

FIgURE 2: Variation of Viscosity with Shear rate.

cantilever bending mode. The storage modulus (E'), loss modulus (E"), and $\tan \delta$ were measured at a frequency of $1 \mathrm{~Hz}$ from ambient to $250^{\circ} \mathrm{C}$ and a heating rate of $5^{\circ} \mathrm{C} / \mathrm{min}$.

3.6. Mechanical Properties Studies. The tensile tests were carried out on dumb-bell-shaped samples using a Hounsfield HS $10 \mathrm{KS}$ (universal testing machine), at room temperature with a gauge length of $35 \mathrm{~mm}$ and crosshead speed of $5 \mathrm{~mm} / \mathrm{min}$. Tensile values reported here were an average of the results for tests run on at least four specimens.

3.7. Field Emission Scanning Electron Microscopy (FESEM). A Carl Zeiss-SUPRA 40 FESEM with an accelerating voltage of $5 \mathrm{kV}$ was employed to observe the morphology of the tensilefractured composites. A thin layer of gold was sputtered on the fracture surface of the specimens for electrical conductivity.

\section{Results and Discussions}

4.1. Rheology. Figure 2 shows the viscosity of PEEK/ LCP/MWNT compounds as a function of shear rate. The reduction of viscosity of PEEK/LCP blend as compared to pure PEEK is attributed to the interfacial slippage between the two polymers in binary blend. This clearly indicates that blending LCP with PEEK facilitates its processability.

Incorporation of MWNTs in the PEEK/LCP blend (PLC) increases the viscosity of the blend over the entire range 
TABLE 1: Sample codes and formulation of nanocomposites.

\begin{tabular}{lcccc}
\hline Sample code & PEEK $(\mathrm{Wt} \%)$ & TLCP $(\mathrm{Wt} \%)$ & Unmodified MWNT $(\mathrm{Wt} \%)$ & SiC-coated MWNT $(\mathrm{Wt} \%)$ \\
\hline PL & 70 & 30 & - & - \\
PLC & 70 & 30 & 1 & - \\
PLS & 70 & 30 & - & 1 \\
\hline
\end{tabular}

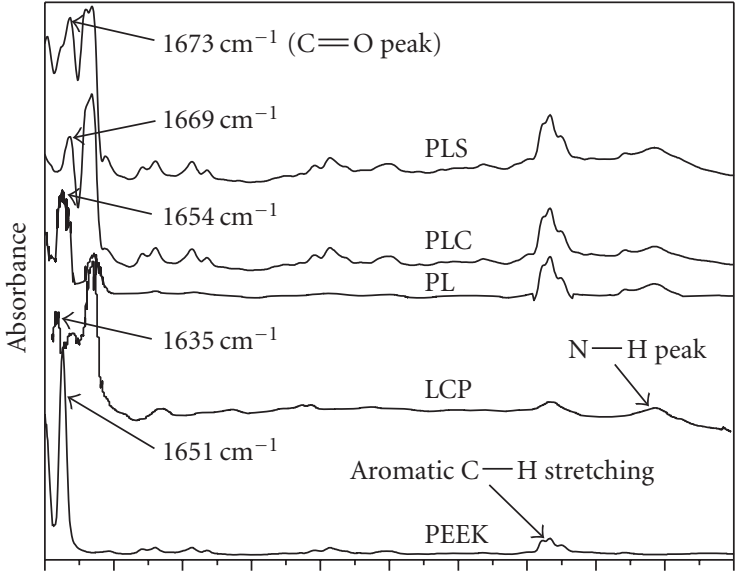

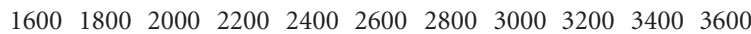
Wavenumber $\left(\mathrm{cm}^{-1}\right)$

Figure 3: FTIR spectra of all the samples with pure PEEK.

of shear rate studied compared to PL. The viscosity of PLS containing SiC-coated MWNT in the PEEK/LCP blend also showed an increase than PL, but comparatively reduced than that of PLC. This indicates that the SiC-coated MWNTs may act as a lubricating agent which reduces the viscosity of PLS as compared to PLC. This phenomenon probably suggests the preferential location of SiC-coated MWNTs at the interfacial boundary. Another possible explanation may at higher shear rate-oriented structure of LCP make it easier to slide past each other which reduces the viscosity [13]. Since PLS shows enhanced fibrillation and orientation of LCP compared to PLC (as shown by FESEM images Figure 7(d)), the viscosity of PLS is lower than PLC. The melt flow index (MFI) of the pure PEEK at $350^{\circ} \mathrm{C}$ under the load of $2.16 \mathrm{~kg}$ is found to be $3.2 \mathrm{~g} / 10 \mathrm{~min}$. The MFI values for the PL, PLC, and PLS samples under the same condition are found to be $4.9 \mathrm{~g} / 10 \mathrm{~min}, 4.4 \mathrm{~g} / 10 \mathrm{~min}$, and $4.6 \mathrm{~g} / 10 \mathrm{~min}$, respectively. This suggests that the processability has been improved with the addition of LCP.

4.2. FTIR Study. Figure 3 exhibits the FTIR spectra of all the samples along with pure PEEK. As can be seen the characteristic carbonyl peak of pure PEEK (at $1651 \mathrm{~cm}^{-1}$ ) [7] has been shifted to the higher value $\left(1654 \mathrm{~cm}^{-1}\right)$ with the addition of LCP and the shift is become more prominent with the addition of MWNTs $\left(1669 \mathrm{~cm}^{-1}\right.$ and $1673 \mathrm{~cm}^{-1}$ for PLC and PLS, resp.). This shift indicates that there is some interaction between PEEK and LCP and this interaction increases with the addition of MWNTs.
4.3. High-Resolution Transmission Electron Microscopy (HRTEM). The dispersion of MWNTs in polymer matrix is one of the most important factors for fabricating highperformance MWNTs/polymer composites. In order to investigate the dispersion of MWNTs and SiC-coated MWNTs in the PEEK/LCP blend system, HR-TEM analysis was carried out upon the microtomed samples of thickness $100 \mathrm{~nm}$. Figures 4(a) and 4(b) show the HR-TEM images of PLC and PLS samples. Agglomerates of MWNTs can be seen in PLC samples while no such agglomerations are visible in PLS samples which conform that SiC-coated MWNTs are uniformly dispersed in the blend system. The formation of agglomerates of MWNTs in the blend system is due to the van der Walls interaction between the MWNTs which is decreased by the SiC coating on the MWNTs, in SiCcoated MWNTs, leading to uniform dispersion of SiC-coated MWNTs in the blend system. The SiC-coated MWNTs show a very rough surface due to the $\mathrm{SiC}$ coating while the surface of pure MWNTs is smooth.

4.4. Thermogravimetric Analysis. To investigate the effect of MWNTs and SiC-coated MWNTs on the thermal properties of PEEK/LCP blend system, TGA was performed on the nanocomposites with same loading of both the fillers. Figure 5 shows the TGA weight loss curve for the blend system and nanocomposites in air. All the nanocomposites show higher thermal stability as compared to the blend system without fillers. The onset degradation temperature of PEEK/LCP blend was found to be $385^{\circ} \mathrm{C}$ (at $2.5 \%$ weight loss) which increases to $420^{\circ} \mathrm{C}$ and $445^{\circ} \mathrm{C}$ with the incorporation of $1 \mathrm{wt} \%$ MWNTs and SiC-coated MWNTs, respectively. The incorporation of MWNTs reduces the chain mobility of the polymer matrix by imposing vast numbers of restriction sites which reduces the thermal vibration of the $\mathrm{C}-\mathrm{C}$ bond $[12]$. So the nanocomposites require more thermal energy for the degradation of the polymer matrix which in turn increases their thermal stability. Another reason for the improved thermal stability of the nanocomposites can be the formation of char, which act as the physical barrier between the polymer and the superficial zone where the combustion of the polymer is occurring [14].

4.5. Dynamic Mechanical Thermal Analysis (DMTA). Figures 6(a) and 6(b) represent the DMTA results. Figure 6(a) shows the variation of storage modulus as a function temperature for PEEK/LCP blend and its composites with MWNTs. The storage modulus curve shows an increase in stiffness of nanocomposites with the incorporation of MWNTs into the PEEK/LCP blend, both below and above the glass transition temperature (around $157^{\circ} \mathrm{C}$ ). This effect is attributed to the 
TABLE 2: Mechanical properties of nanocomposites.

\begin{tabular}{lccc}
\hline Sample code & Tensile strength $(\mathrm{MPa})$ & Elongation at break $(\%)$ & Young's modulus $(\mathrm{GPa})$ \\
\hline PL & 79.2 & 19.8 & 6.7 \\
PLC & 89.1 & 9.1 & 7.3 \\
PLS & 109.3 & 5.2 & 7.5 \\
\hline
\end{tabular}

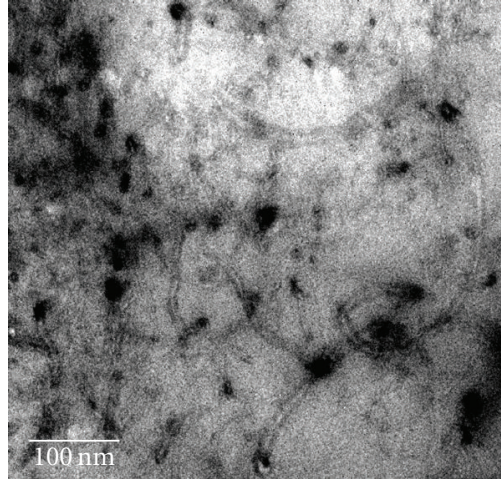

(a)

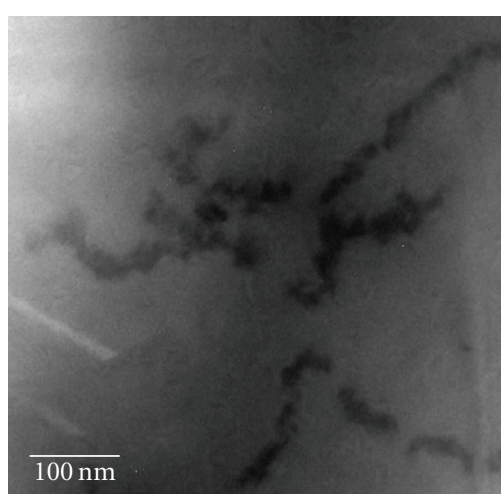

(b)

FIgURE 4: HR-TEM image of (a) PLC and (b) PLS.

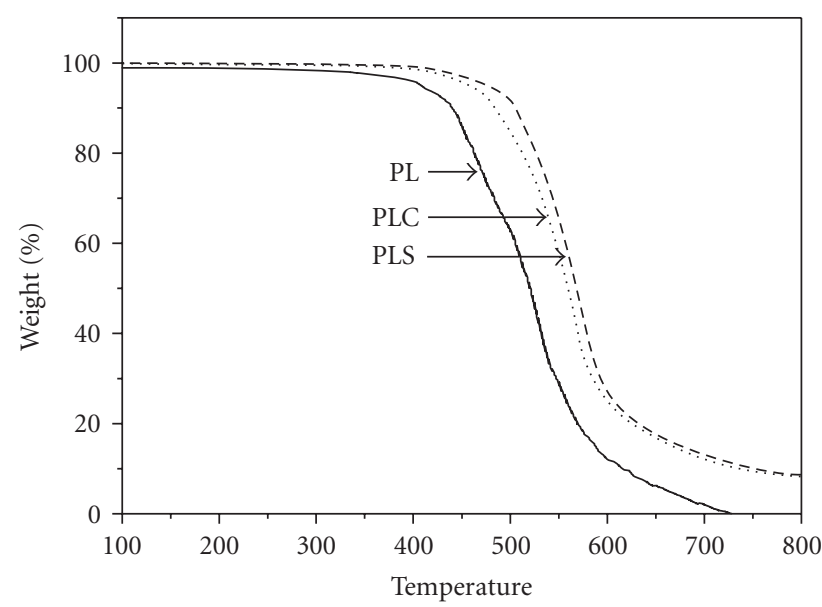

FIGURE 5: TGA curves of PEEK/LCP/MWNTs nanocomposites. decrease in the polymer chain mobility due to the incorporation of MWNTs. Also MWNTs act as a cross-linking site between the LCP droplets and polymer matrix (as revealed by FESEM) which increases the stiffness of the nanocomposites. The significant improvement in storage modulus of PLS nanocomposites than the PLC is ascribed to the uniform dispersion of the SiC-coated MWNTs in the blend system (as revealed by TEM).

The tan $\delta$ curve for the PEEK/LCP blend and nanocomposites is shown in Figure 6(b). As can be seen the glass transition temperature ( $\mathrm{Tg}$ ) shifts to the higher value with the incorporation of MWNTs. The pure blend system shows a Tg of $157^{\circ} \mathrm{C}$, which increases to 168 and $175^{\circ} \mathrm{C}$ for PLC and PLS nanocomposites, respectively. The increase in $\mathrm{Tg}$ is attributed to the immobilize action of MWNTs at high temperature. In the glass transition region these MWNTs act as a barrier to the viscous flow of the polymer chains, which leads to the improvement in $\mathrm{Tg}$.

With the incorporation of MWNTs, the $\tan \delta$ peak height decreases as compared to the pure blend system which suggests improved damping behavior of the nanocomposites with minimum heat buildup. With the incorporation of MWNTs into the blend system, a greater amount of stress is transferred to the MWNTs and a very small stress is available to strain the interface which leads to less energy dissipation. The reduced peak height of the PLS than the PLC nanocomposites suggests that there must be better adhesion between the SiC-coated MWNTs and matrix than that of pure MWNTs with matrix [15].

4.6. Mechanical Properties. Tensile tests were performed on the compression molded samples to study the effect of incorporation of MWNTs into the PEEK/LCP blend system. The results of tensile tests were summarized in Table 2. As can be seen from the results, the young's moduli of the nanocomposites are higher than the PEEK/LCP blend. The tensile modulus of the PEEK/LCP blend was found to be $6.7 \pm 0.1 \mathrm{GPa}$ and increased by $9 \%$ to $7.3 \mathrm{GPa}$ and $12 \%$ to $7.5 \mathrm{GPa}$ for the incorporation of $1 \mathrm{wt} \%$ of MWNTs and $\mathrm{SiC}$-coated MWNTs into the blend system, respectively. The corresponding tensile strength increased by $12.5 \%$ and $38 \%$ as compared to pure blend system. But the percentage of elongation decreases from $19.8 \%$ to $9.1 \%$ and $5.2 \%$ for PLC and PLS samples, respectively. This might be due to the decrease of ductility of the polymer blend with the incorporation of MWNTs.

4.7. Field Emission Scanning Electron Microscopy (FESEM). Figures $7(\mathrm{a})-7(\mathrm{~d})$ show the FESEM images of tensile fractured surface of the PL, PLC, and PLS samples. 


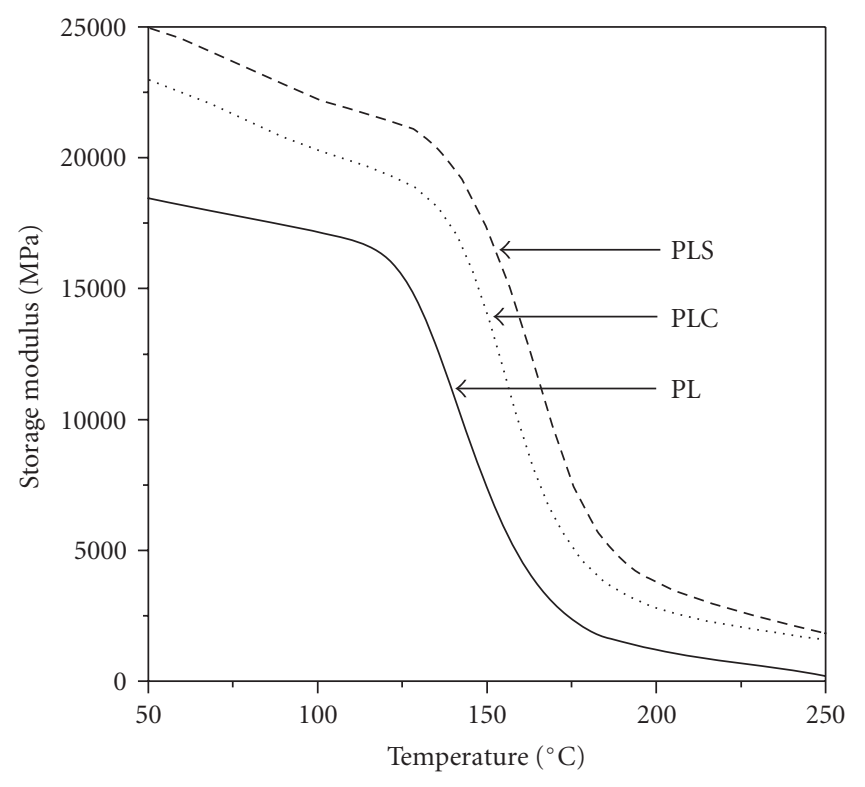

(a)

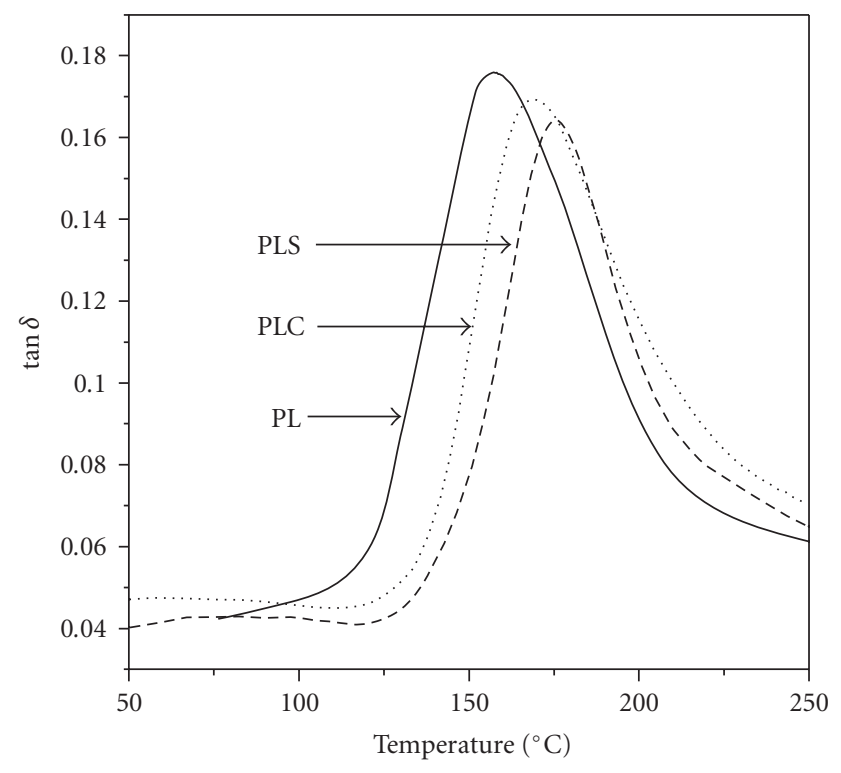

(b)

FIgURE 6: (a) Storage modulus, (b) tan $\delta$ versus temperature plots of PEEK/LCP/MWNTs nanocomposites.

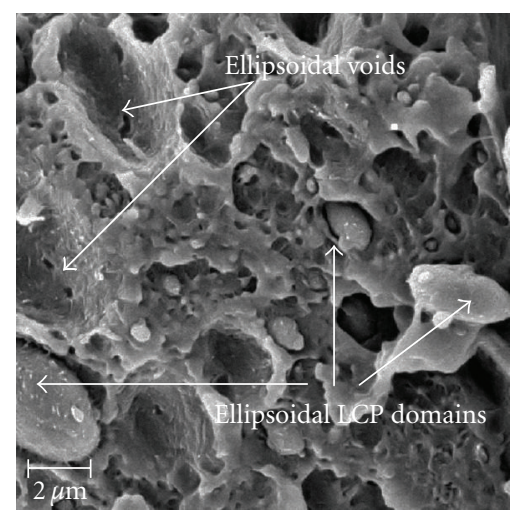

(a)

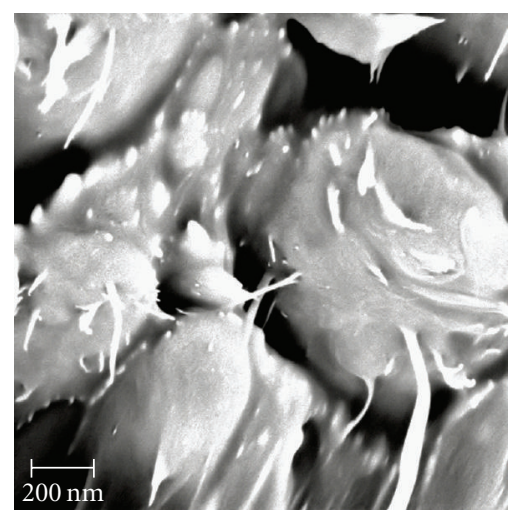

(c)

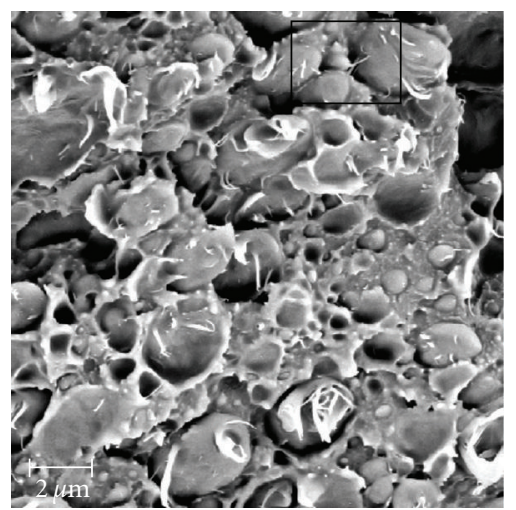

(b)

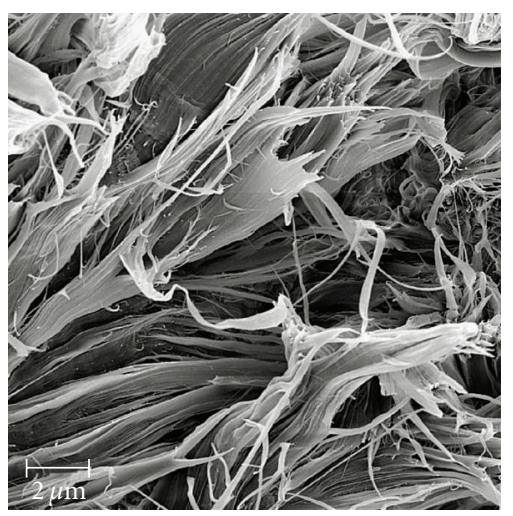

(d)

FIGURE 7: FESEM images of tensile fractured surfaces of (a) PL, (b), (c) PLC, and (d) PLS samples. 
As can be seen from Figure 7(a), for PL blend system ellipsoidal domains of LCP of various dimensions are uniformly dispersed in the PEEK matrix. The voids seen in the image are formed due to the pullout of the LCP domains from the PEEK matrix which suggests poor interfacial adhesion between the two matrixes. Due to this low interfacial adhesion the stress transfer from the PEEK matrix to LCP domains is not sufficient enough for LCP fibrillation in the blend system.

Figure 7(b) reveals that, with the incorporation of MWNTs, some fibrillation of the LCP domains has been occurring in the composite system. A close-up of the PEEK/LCP interface is shown in Figure 7(c). This image shows that the MWNTs act as the bridging element between the LCP droplets and polymer matrix which leads to effective stress transfer from the PEEK matrix to the LCP droplets leading to the fibrillation of LCP. Same types of results are obtained by Chen et al. where $\mathrm{CaCO}_{3}$ whisker enhanced the fibrillation of LCP [16]. This effect is become more prominent with the incorporation of SiC-coated MWNTs due to the uniform dispersion of the fillers and rough surface of the SiC-coated MWNTs (as revealed by TEM images). The rough surface of the SiC-coated MWNTs produces effective physical interaction between the LCP and PEEK phases and reduces the slippage of MWNTs which in turn increases the stress transfer from the PEEK phase to LCP droplets leading to the complete deformation of LCP droplets into LCP fibers (Figure 4(d) ).

\section{Conclusion}

PEEK/LCP/MWNTs and PEEK/LCP/SiC coated MWNTs nanocomposites were prepared by melt blending process. Rheology study shows that SiC-coated MWNTs act as lubricating agent which reduces the viscosity of the PLS samples as compared to the PLC samples. SiC-coated MWNTs show better dispersion than the pure MWNTs, in the blend system, as revealed by HR-TEM. The fibrillation of LCP increased with the incorporation of MWNTs and the effect is more prominent for SiC-coated MWNTs-filled system. Nanocomposites with SiC-coated MWNTs show higher mechanical properties than the pure MWNTs-filled system.

\section{References}

[1] L. A. Utracki, Polymer Blends Handbook, vol. 1, Kluwear Academic Publishers, Amsterdam, The Netherlands, 2002.

[2] A. Siegmann, A. Dagan, and S. Kenig, "Polyblends containing a liquid crystalline polymer," Polymer, vol. 26, no. 9, pp. 13251330, 1985.

[3] E. G. Joseph, G. L. Wilkes, and D. G. Baird, "Effect of flow history on the morphology of thermotropic liquid crystalline copolyesters," Polymer Engineering and Science, vol. 25, no. 7, pp. 377-388, 1985.

[4] K. G. Bilizard and D. G. Baird, "The morphology and rheology of polymer blends containing a liquid crystalline copolyester," Polymer Engineering and Science, vol. 27, no. 9, pp. 653-662, 1987.
[5] A. T. Isayev and M. J. Modic, "Self-reinforced melt processible polymer composites: extrusion, compression, and injection molding," Polymer Composites, vol. 8, no. 3, pp. 158-175, 1987.

[6] F. N. Cogswell, Thermoplastic Aromatic Polymer Composites, Butterworth Heinemann, Oxford, UK, 1992.

[7] T. Rath, S. Kumar, R. N. Mahaling, et al., "Flexible composite of PEEK and liquid crystalline polymer in presence of polyphosphazene," Journal of Applied Polymer Science, vol. 104, no. 6, pp. 3758-3765, 2007.

[8] J. Sandler, P. Werner, M. S. P. Shaffer, et al., "Carbonnanofibre-reinforced poly(ether ether ketone) composites," Composites Part A, vol. 33, no. 8, pp. 1033-1039, 2002.

[9] R. A. Crick, D. C. Leach, P. J. Meakin, and D. R. Moore, "Interlaminar fracture morphology of carbon fibre/PEEK composites," Journal of Materials Science, vol. 22, no. 6, pp. 2094-2104, 1987.

[10] S. K. Park, S. H. Kim, and J. T. Hwang, "Carboxylated multiwall carbon nanotube-reinforced thermotropic liquid crystalline polymer nanocomposites," Journal of Applied Polymer Science, vol. 109, no. 1, pp. 388-396, 2008.

[11] S. Bose, M. Mukherjee, K. Pal, G. C. Nayak, and C. K. Das, "Development of core-shell structure aided by $\mathrm{SiC}$ coated MWNT in ABS/LCP blend," Polymers for Advanced Technologies. In press.

[12] K. Lozano and E. V. Barrera, "Nanofiber-reinforced thermoplastic composites. I. Thermoanalytical and mechanical analyses," Journal of Applied Polymer Science, vol. 79, pp. 125133, 2001.

[13] A. Mehta and A. I. Isayev, "Rheology, morphology, and mechanical characteristics of poly(ether ether ketone)-liquid crystal polymer blends," Polymer Engineering and Science, vol. 31, no. 13, pp. 971-980, 1991.

[14] G. Beyer, "Flame retardant properties of EVA-nanocomposites and improvements by combination of nanofillers with aluminium trihydrate," Fire and Materials, vol. 25, no. 5, pp. 193197, 2002.

[15] S. Kumar, T. Rath, R. N. Mahaling, M. Mukherjee, B. B. Khatua, and C. K. Das, "Multi-Walled Carbon Nanotubes/Polymer Composites in Absence and Presence of Acrylic Elastomer (ACM)," Journal of Nanoscience and Nanotechnology, vol. 9, no. 5, pp. 2981-2990, 2009.

[16] J. Chen, P. Chena, L. Wu, et al., "Enhanced fibrillation of LCP by $\mathrm{CaCO}_{3}$ whisker in polysulfone matrix through increasing elongational stress," Polymer, vol. 47, no. 15, pp. 5402-5410, 2006. 

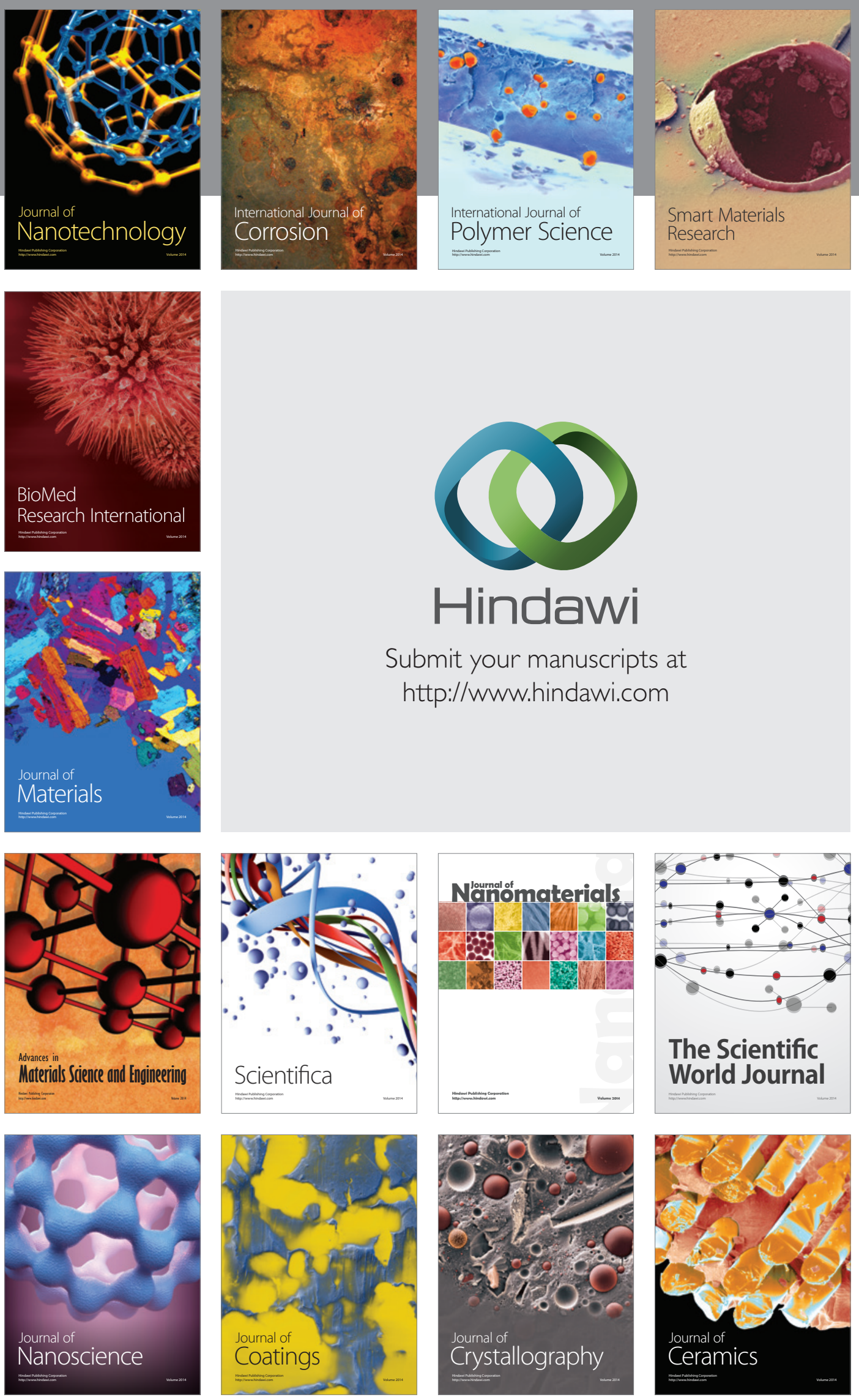

The Scientific World Journal

Submit your manuscripts at

http://www.hindawi.com

\section{World Journal}

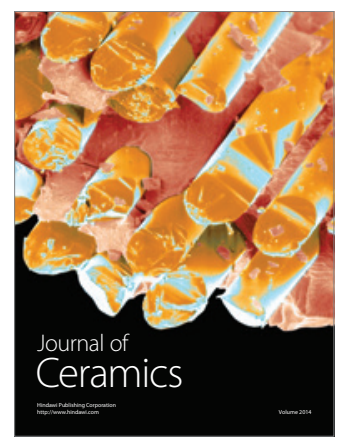

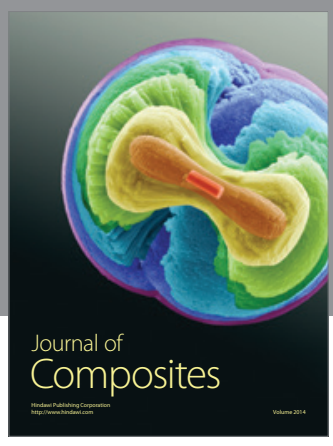
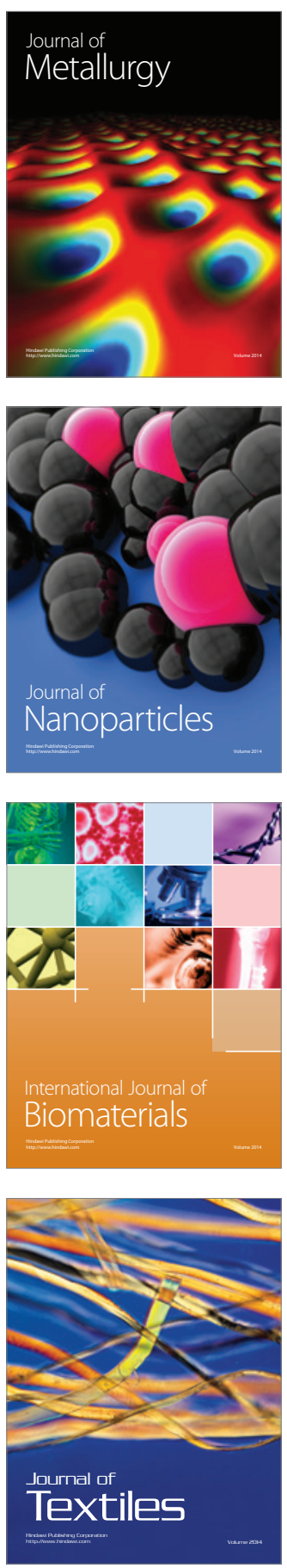